\title{
YER FISTIĞI (Arachis Hypogaea L.) YAĞININ FARKLI ÇÖZÜCÜLER KULLANILARAK DEĞİŞKEN GÜÇ VE FREKANSLARDA ULTRASON DESTEKLII EKSTRAKSIYYNU
}

\author{
Onur Ketenoğlu* \\ Çankır1 Karatekin Üniversitesi, Gıda Mühendisliği Bölümü, Çankırı, Türkiye
}

Geliş / Received: 10.10.2019; Kabul / Accepted: 13.01.2020; Online bask1 / Published online: 19.01.2020

Ketenoğlu, O. (2020). Yer fistığı (Arachis Hypogaea L.) yağının farklı çözücüler kullanılarak değişken güç ve frekanslarda ultrason destekli ekstraksiyonu. GIDA (2020) 45 (1): 61-71 doi: 10.15237/gida.GD19132

Ketenoğlu, O. (2020). Ultrasound-assisted extraction of peanut (Arachis Hypogaea L.) oil under varying power and frequencies using different solvents. GIDA (2020) 45 (1): 61-71 doi: 10.15237/gida.GD19132

\section{ÖZ}

Bu çalışmada, ultrason destekli ekstraksiyonla elde edilen yer fistı̆̆ı yağının ekstrakiyon verimi ve yağ asidi bileşimi üzerine farklı frekans ve ultrasonik gücün etkileri incelenmiştir. Ayrıca yağ ekstraksiyonunda yaygın olarak tercih edilen hekzan yerine, daha az toksik ve çevreye daha duyarlı bir çözücü olan etanolün kullanılabilirliği araştırılmıştır. Etanol ve hekzana ait en yüksek ekstraksiyon verimleri $37 \mathrm{kHz}$ frekans ve $\% 80$ güçte elde edilmiştir ve sırasıyla \%40.55 ve \%45.19 olarak hesaplanmıştır. Hekzan verimlerinin tüm örneklerde etanole göre yüksek olduğu tespit edilmiştir. $37 \mathrm{kHz}$ ve $80 \mathrm{kHz}$ frekanstaki etanol ekstraktlarının verimleri arasındaki fark istatistik olarak önemli bulunmuştur. Varyans analizi sonucunda, hekzan verimleri üzerine yalnızca frekansın etkili olduğu belirlenirken, etanol verimleri üzerine işlem koşullarının interaksiyon etkileri tespit edilmiştir. Bulgular frekans artışının verimde azalmaya neden olduğunu ortaya koymaktadır. Ayrıca, uygulanan farklı işlem koşullarının yağ asidi bileşiminde önemli bir etki göstermediği tespit edilmiştir.

Anahtar kelimeler: Ultrason destekli ekstraksiyon, etanol, yer fistığı yağı, oleik asit, frekans, ultrasonik güç

\section{ULTRASOUND-ASSISTED EXTRACTION OF PEANUT (Arachis Hypogaea L.) OIL UNDER VARYING POWER AND FREQUENCIES USING DIFFERENT SOLVENTS}

\begin{abstract}
The effects of extraction frequency and ultrasonic power on the extraction yield and fatty acid composition of peanut oil were studied. Also, the usability of ethanol as a less toxic and environmentally friendly alternative to hexane -the most common solvent in conventional oil extraction- was investigated. The highest extraction yields for ethanol and hexane were respectively $\% 40.55$ and $\% 45.19$ at $37 \mathrm{kHz}$ frequency and $80 \%$ ultrasonic power. It was determined that all samples extracted with hexane had higher extraction yields than those of ethanol. The differences between the ethanolic extraction yields at 37 and $80 \mathrm{kHz}$ were statistically significant. The major factor affecting the extraction yield was the frequency for hexane; while interactional effects of all process conditions were significant for ethanolic extraction. The increment of ultrasonic frequency caused a decrease in the extraction yields. Results revealed that different processing conditions did not significantly affect fatty acid compositions.
\end{abstract}

Keywords: ultrasound-assisted extraction, ethanol, peanut oil, oleic acid, frequency, ultrasonic power

\footnotetext{
* Yazışmalardan sorumlu yazar / Corresponding author;

$\square$ ketenoglu@karatekin.edu.tr, $\quad$ (+90) 376218 9532,

島 $(+90) 3762189536$
}

Onur Ketenoğlu; ORCID no: 0000-0001-7584-8389 


\section{GİRİ̧̧}

Yer fistığ1 (Arachis bypogaea L.), baklagiller familyasına ait Güney Amerika kökenli tek y1llık bir bitki olup, bileşiminde \%55'e varan oranlarda yağ içerebilmektedir (Kadiroğlu, 2018). Yer fistığının insan diyetindeki önemi, içerdiği bu yağın büyük miktarının sağlık üzerine olumlu etkileri bilimsel olarak araştırılmış ve raporlanmış olan tekli (oleik asit) ve çoklu (linoleik asit) doymamış yağ asitlerinden oluşmasıdır. Yer fistığının bazı rapor edilen oleik ve linoleik asit konsantrasyonları sırasıyla şu şekildedir: \%69 ve $\% 43$ (Rodriguez-Estrada vd., 2017), \%45-60 ve \%20-40 (Kadiroğlu, 2018), \%35-69 ve \%12-43 (Anonim, 2012), \%58 ve \%21 (Aluyor vd., 2009). Bugün dünyada en fazla yer fistlğı üretimine sahip ülkeler arasında Çin ve Hindistan öne çıkmaktadır. Türkiye'nin 2017 FAO verilerine göre, kabuklu yer fistığı hasadı yapılan alan1 40 bin hektar civarinda olup, üretim kapasitesi ise 165 bin tondur (FAO, 2019). Çin, ülkemize kıyasla ortalama 104 kat daha fazla üretim kapasitesine sahip olup, FAO verilerine göre 2017 yll üretim miktarı yaklaşı 17 milyon tondur (FAO, 2019). Bilimsel veriler ışı̆̆ında bu yağların sağlık açısından elzem olan yağ asitleri bakımından zengin olmas1 dolayıs1 ile üretim ve tüketimi dünyada yaygındır.

Yer fistığı yağı, yüksek sıcaklığa dayanıklı olup, kızartma işleminde rahatlıkla kullanılabilen bir yağdır (Onat, 2018). Piyasada genellikle rafine edilmiş olarak satşsa sunulan bu yağ, tüketicinin işlem görmemiş ve dolayısıyla kalitesinde değişim meydana gelmemiş soğuk sıkım yağ talebine istinaden soğuk pres yöntemiyle de elde edilebilmektedir. Ancak, herhangi bir rafinasyon uygulanmamış yer fistığ1 yağı tüketicinin algisında olumsuz etki bırakabilecek yoğun karakteristik tat ve kokuya sahiptir. Ayrıca rafinasyon işlemi, ekstraksiyon sırasında yer fistığından yağa geçebilecek bazı alerjenlerin de etkisinin azaltılmas1 veya ortadan kaldırlmasinda da rol oynamaktadır (Crevel vd., 2000).

Bununla birlikte geleneksel yöntemlerden farklı olarak, yağlı tohum ve meyvelerden yağ eldesinde ısıl olmayan yenilikçi teknolojilerin kullanımı giderek önem kazanmaktadır.
Bu teknolojiler arasinda popülarite kazanmış olan ultrason destekli ekstraksiyon yöntemi daha az süre, enerji ve çözücü gereksinimi ve daha yüksek saflıkta ürün eldesi bakımından iyi bir alternatif olarak öne çımaktadır (Chemat vd., 2008). Ultrason destekli ekstraksiyonda, ultrasonik banyo veya sonikatör problar kullanılarak çeşitli frekanslarda ses dalgaları üretilmekte ve bu ses dalgaları biyolojik materyal üzerine gönderilerek akustik kavitasyon yaratılmaktadır. Bunun sonucunda hücre yapisı bozulmakta ve bileşenlerin açığa çıkması sağlanmakta, böylece ekstraksiyon gerçekleştirilmektedir. Temizleme, çözündürme, homojenizasyon, gaz giderme (degassing), emülsiyon oluşturma gibi farklı amaçlar için de kullanilabilen ultrason teknolojisinin ekstraksiyon amaciyla kullanımının diğer avantajları arasında; daha hızlı kütle ve enerji transferi, seçici ekstraksiyon, daha küçük boyutlu ekipman kullanımı, daha homojen ekstraksiyon ortamı oluşturulması ve ekstraksiyon boyunca sicaklık ve konsantrasyon gradyanı oluşmaması sıralanabilir (Chemat vd., 2008). Tüm bu sıralanan özellikleri bakımından ultrason destekli ekstraksiyon yöntemi, yağ ekstraksiyonu ile sınırlı kalmamış ve bir çok gida ürününde kendine uygulama alanı edinmiştir. Bu uygulamalara; çaydan fenolik bileşenlerin ekstraksiyonu (Afroz Bakht vd., 2019), üzüm çekirdeğinden yağ ve fenolik bileşen ekstraksiyonu (Da Porto vd., 2013), medikal bitkilerden antioksidan madde ekstraksiyonu (Dong vd., 2010), mikroalglerden yağ ekstraksiyonu (Escorsim vd., 2018), ultrason destekli kurutma prosesleri (Topdaş ve Ertugay, 2013; Tüfekçi ve Özkal, 2015), ve çeşitli yağlı materyallerden yağ ekstraksiyonu (Chanioti ve Tzia, 2017; Li vd., 2004; Ma vd., 2019; Perrier vd., 2017; Taticchi vd., 2019) örnek olarak gösterilebilir.

Petrol türevi bir bileşen olan hekzan polar olmayan yapısı, yağa karşı olan yüksek seçiciliği ve çözücü kabiliyeti nedeniyle, günümüzde geleneksel yağ ekstraksiyonunda en çok tercih edilen çözücüdür. Bununla birlikte, hekzan kullanımının insan sağlığı ve çevre üzerine olumsuz bir çok etkisi rapor edilmiştir. Yanıcı ve tahriş edici özelliklerinin yanı sıra, üreme 
sistemleri üzerine olan olumsuz etkisi ve çevre açısından tehlikeli bir bileşen olduğu bildirilen hekzana uzun süreli maruz kalmanın merkezi sinir sistemini de olumsuz etkilediği ifade edilmiştir ( $\mathrm{Li}$ vd., 2014). Bu sebeplerden ötürü, rafinasyon sonrasında yağda kalıntı olarak bulunabilen bu çözücünün yerine geçebilecek alternatif çözücü arayışları üzerine olan ilginin arttığ1 belirtilmektedir (Baümler vd., 2016). Bu alternatifler arasinda ise petrol türevleri yerine çeşitli bitkisel kaynaklardan elde edilen, daha güvenli ve toksisitesi düşük alkol türevleri ön plana çıkmaktadır.

Bu çalışmanın amacı, yenilikçi ve 1sıl olmayan bir teknoloji olan ultrason destekli ekstraksiyon tekniğinde değişken işlem koşullarının (frekans ve güç) elde edilen ekstraktlar üzerine etkilerinin irdelenmesi ve ayrıca hekzan alternatifi olarak öne sürülebilecek etanolün farklı işlem koşullarında yer fistığ1 yağ1 ekstraksiyonundaki kullanılabilirliğinin incelenmesidir.

\section{MATERYAL VE YÖNTEM \\ Materyal}

Çalışmada hammadde olarak kullanılan ve herhangi bir ön işleme tabi tutulmamış (tuzlanmamış, kavrulmamış) çiğ yer fistıkları Çankırı'daki yerel marketlerden satın alınmıştır. Fistıklardan yağ ekstraksiyonu amaciyla kullanılan analitik saflıktaki etanol ve $n$-hekzan Merck firmasindan (Merck KGaA, Darmstadt, Almanya) temin edilmiştir. Yağ asidi metil esteri karışımı (Supelco ${ }^{\circledR}, 37$ Component FAME Mix) ve yağ asitlerini esterleştirme için gerekli analitik saflıktaki diğer kimyasallar ise Sigma-Aldrich firmasindan (Sigma-Aldrich, St. Louis, A.B.D) temin edilmiştir.

\section{Ultrason destekli ekstraksiyon}

Çiğ yer fistıkları bir kahve değirmeni (Sinbo SCM2934, Türkiye) yardımıyla öğütüldükten sonra, $10 \pm 0.05 \mathrm{~g}$ numune $100 \mathrm{~mL}$ ölçekli cam bir behere aktarılarak üzerine $90 \mathrm{~mL}$ çözücü ilave edilmiştir. Çözücü olarak etanol ve $n$-hekzan seçilmiştir. Beherler daha sonra maksimum çıkış gücü $580 \mathrm{~W}$ olan sıcaklık kontrollü bir ultrasonik su banyosunun (Elmasonic P60-H, Elma Schmidbauer GmbH, Almanya) merkez noktasına yerleştirilmiştir. Denemede uygulanan değişken ultrasonik frekans ve güç değerleri ile diğer sabit parametreler aşağıdaki gibidir:

-Ekstraksiyon süresi: 8 dakika

-Ekstraksiyon sicaklığ: $30 \pm 2{ }^{\circ} \mathrm{C}$

-Ultrasonik güç: \%60 (348 W), \%80 (464 W), $\% 100(580 \mathrm{~W})$

-Ultrason frekansi: 37 ve $80 \mathrm{kHz}$

Ultrasonik ekstraksiyon sırasında sicaklık yükselmesinin önüne geçmek için buz tamponlar kullanılmıştır. Ekstraksiyonu tamamlanan numuneler bir balona aktarıldıktan sonra içerisindeki çözücü döner buharlaştırıcıda (HeiVAP Precision ML/G1, Heidolph Instruments $\mathrm{GmbH} \& \mathrm{CO} . \mathrm{KG}$, Almanya) $50{ }^{\circ} \mathrm{C}$ sicaklik ve 150-200 mbar vakum altında uzaklaştırılmıştır. Daha sonra, elde edilen ekstraktlarda mevcut olabilecek çözücü kalıntılarını uzaklaştırmak amacıyla numuneler $40{ }^{\circ} \mathrm{C}$ sicaklıktaki etüvde (Wisd Thermostable, Daihan Scientific, Kore) bir gece bekletilmiştir. Elde edilen numunelere ait ekstraksiyon verimleri Denklem 1'de verildiği şekilde hesaplanmı̧tır:

$\operatorname{Verim}(\%)=\left(\frac{m_{e}}{m_{b}}\right) \times 100 \quad$ Denklem (1)

$\mathrm{Bu}$ denklemde, $m_{\boldsymbol{e}}$ : elde edilen ekstraktın ağırlığını, $m_{b}$ : numunelerin başlangıçtaki ağırlığını ifade etmektedir.

Yağ asidi dağılımının gaz kromatografi (GC) ile belirlenmesi

Ekstraktların yağ asidi bileşiminin belirlenebilmesi için öncelikle numuneler ISO standart yöntemde (No: 12966-2:2011) (ISO, 2011) açılanan şekilde yağ asidi metil esterleri formuna dönüştürülmüştür. Hazırlanan esterler, üzerinde alev iyonlaştırmalı dedektöre (FID) bağlı $60 \mathrm{~m}$ uzunluk $\times 0.25 \mathrm{~mm}$ iç çap $\times 0.20 \mu \mathrm{m}$ film kalınlığına sahip bir TR-CN100 (Teknokroma, İspanya) kapiler kolon bulunan bir Shimadzu GC2010 Plus gaz kromatografi cihazina (Shimadzu, Japonya) enjekte edilmiştir. Gaz kromatografi cihazına ait yöntem parametreleri aşağıdaki gibidir:

-Enjeksiyon bloğu sıcaklığı: $230{ }^{\circ} \mathrm{C}$

-Kolon firını sıcaklığı: $190{ }^{\circ} \mathrm{C}$ 
-Dedektör sıcaklığı: $240{ }^{\circ} \mathrm{C}$

-Kolon akış hızı: $0.10 \mathrm{~mL} / \mathrm{dk}$

-Akış modu: Split (Split oranı 1:150)

-Taşıyıcı gaz: Helyum

Elde edilen piklerin tanımlanması için yă̆ asidi metil esteri karışımından (37 Component FAME Mix) ve ön çalışmalardan faydalanılmıştır.

\section{İstatistiksel analiz}

Tüm ekstraksiyon işlemleri ve GC analizleri 2 tekerrürlü olacak şekilde yapılmıştır. Elde edilen veriler ortalama \pm standart hata şeklinde ifade edilmiştir. Farklı çözücüler kullanarak farklı ultrasonik koşullarda gerçekleştirilen ekstraksiyonların, elde edilen ekstraktların oleik asit miktarı ve ekstraksiyon verimleri üzerindeki etkileri Minitab 16 paket program1 (Minitab Inc., A.B.D.) yardımıyla yapılan çift yönlü varyans analizi (Two-Way ANOVA) ile belirlenmiştir. Varyans analiz tabloları oluşturulurken uygulanan frekans, ultrasonik güç ve bunların interaksiyonlarının ortalamalar üzerindeki öneminin istatistiksel olarak incelenmesindeki güven aralığ1 \%95 olarak belirlenmiştir. İstatistik olarak önemli olduğu tespit edilen ortalamaların çoklu karşılaştırmalarında ise yine $\% 95$ güven aralığına sahip Tukey testi uygulanmıştır.

\section{BULGULAR VE TARTIŞMA}

\section{Ekstraksiyon verimi}

Yapılan çalışmada, bir yandan ultrason destekli ekstraksiyon işleminde değişken ultrasonik güç ve frekanslarının yer fistı̆̆ yağı ekstraksiyonuna olan etkileri incelenirken, diğer yandan yă̆ ekstraksiyonunda geleneksel olarak kullanilan hekzanın yanı sıra toksisitesi daha az ve daha çevre dostu olan bir çözücü olarak etanolün kullanılabilirliği araştırılmıştır. Elde edilen bulgulara göre, tüm çalışma boyunca hekzan ile ekstrakte edilen örneklerin ekstraksiyon verimleri etanol ile ekstrakte edilen gruba göre daha yüksek bulunmuştur (Çizelge 1). Kullanılan çözücüler karşılaştırıldığında, etanol ve hekzana ait en yüksek verimler $37 \mathrm{kHz}$ ve $\% 80$ güçte elde edilmiş olup, sirasiyla $\% 40.55$ ve $\% 45.19$ olarak tespit edilmiștir.

Çizelge 1. Farklı koşullarda gerçekleştirilen ekstraksiyonlara ait verimler (\%) Table 1. Yields of extractions performed at different conditions (\%)

\begin{tabular}{|c|c|c|c|}
\hline \multirow{2}{*}{$\begin{array}{l}\text { Frekans Frequency } \\
\qquad(\mathrm{kHz})\end{array}$} & \multirow{2}{*}{$\begin{array}{l}\text { Ultrasonik güç } \\
\text { Ultrasound power }(\%)\end{array}$} & \multicolumn{2}{|c|}{$\begin{array}{l}\text { Verim } \\
\text { Yield }\end{array}$} \\
\hline & & $\begin{array}{l}\text { Etanol } \\
\text { Ethanol }\end{array}$ & $\begin{array}{l}\text { Hekzan } \\
\text { Hexane }\end{array}$ \\
\hline \multirow[b]{2}{*}{37} & 60 & $14.42 \pm 0.40^{\mathrm{B}}$ & $43.10 \pm 0.54 \mathrm{ab}$ \\
\hline & $\begin{array}{c}80 \\
100 \\
\end{array}$ & $\begin{array}{l}40.55 \pm 3.27^{\mathrm{A}} \\
39.01 \pm 1.83^{\mathrm{A}}\end{array}$ & $\begin{array}{l}45.19 \pm 0.54^{\mathrm{a}} \\
44.49 \pm 1.22^{\mathrm{a}}\end{array}$ \\
\hline \multirow[b]{2}{*}{80} & 60 & $4.48 \pm 0.87 \mathrm{C}$ & $29.65 \pm 1.32^{\mathrm{c}}$ \\
\hline & $\begin{array}{c}80 \\
100 \\
\end{array}$ & $\begin{array}{l}4.68 \pm 0.17^{C} \\
4.52 \pm 0.10^{C}\end{array}$ & $\begin{array}{l}36.91 \pm 2.33^{\mathrm{abc}} \\
32.63 \pm 4.00^{\mathrm{bc}}\end{array}$ \\
\hline \multicolumn{4}{|c|}{$\begin{array}{l}\text { *Veriler ortalama } \pm \text { std.hata şeklinde ifade edilmiştir }(\mathrm{n}=2) \text {. } \\
\text { **Farklı büyük harfleri }(\mathrm{A}, \mathrm{B}, \mathrm{C}, . .) \text { taşyan ortalamalar çözücü olarak etanol kullanilan örneklere ait olup, } \\
\text { aralarındaki fark istatistik olarak önemlidir }(P<0.05) \text {. } \\
\text { ***Farklı küçük harfleri }(\mathrm{a}, \mathrm{b}, \mathrm{c}, . .) \text { taşyan ortalamalar çözücü olarak hekzan kullanilan örneklere ait olup, } \\
\text { aralarındaki fark istatistik olarak önemlidir }(P<0.05) \text {. } \\
\text { * Values are expressed as mean } \pm \text { std.error }(n=2) \text {. } \\
\text { ** Difference between means baving different uppercase letters for ethanolic extraction are statistically significant }(P<0.05) \text {. } \\
\text { *** Difference between means having different lowercase letters for bexane extraction are statistically significant }(P<0.05) \text {. }\end{array}$} \\
\hline
\end{tabular}


Uygulanan ultrasonik güç sabit tutulduğunda, her iki grubun $37 \mathrm{kHz}$ frekanstaki ekstraksiyon verimleri $80 \mathrm{kHz}$ 'teki verimlere göre daha yüksek bulunmuştur. Örneğin, 37 kHz frekansta \%60 güç uygulandığında etanol ve hekzanin ekstraksiyon verimleri sirasiyla $\% 14.42$ ve $\% 43.10$ olarak tespit edilmişken, aynı güçte frekans $80 \mathrm{kHz}$ 'e çıkarıldığında etanol ve hekzan verimlerinde sırasıyla \%69 ve \%31.2 oranında düşüş saptanmıştır.

Her iki grubun ekstraksiyon verimlerinde her iki frekansta da, uygulanan güç \%60'tan \%80'e çıkarıldığında artış gözlenmiş, ancak uygulanan güç \%100'e çıkarıldığında gözlenen düşüşün istatiksel olarak önemli olmadığ tespit edilmiştir $(P>0.05)$. Çizelge 1'e göre, etanol ekstraksiyonu ile elde edilen en düşük verim $\% 4.48$ ile $80 \mathrm{kHz}$ frekans ve $\% 60$ güç uygulamasında elde edilirken, hekzana ait en düşük verim ise yine aynı ekstraksiyon koşullarında \%29.65 olarak bulunmuştur.

Literatür verileri incelendiğinde, ekstraksiyon verimleri kullanılan çözücüye göre kıyaslandığında -kullanılan materyal ve yöntemler değişmekle birlikte- hekzan veriminin etanole göre düşük olduğunu (Breil vd., 2016) ya da verimler arasında önemli bir fark olmadığını belirten çalışmalar (Sbihi vd., 2018) mevcut olsa da, genel olarak kabul edilen kanı, bu çalışmanın sonuçlarına benzer şekilde hekzan veriminin etanol veriminden daha yüksek olduğudur (Ferreira-Dias vd., 2003; Li vd., 2014; Zhuang vd., 2018). Li vd. (2014), etanol veriminin hekzandan daha düşük olmasının sebebini çözücü polariteleri arasındaki farklılık ile açıklamaktadır. Araştırıcılar, terpen ve alkol gibi maddelerin genellikle $n$-hekzandan daha polar olduklarını ifade etmişlerdir. Ayrıca, etanolün hekzana göre daha az seçici bir çözücü olması sonucunda yağ dışı diğer bileşenleri de çözerek bünyesine kattığı düşünülmektedir. Bunun sonucu olarak bu çalışmadaki göze çarpan diğer bir nokta, hekzan ile elde edilen ekstraktların daha yağa benzer bir yapıya sahip oldukları, buna karşın etanol ekstraktlarının ise daha katı ve sürülebilir bir yapıya sahip olduklarıdır. Nitekim, etanolün daha az seçici olduğu gerçeği daha önceden yapılan çalışmalarda da ifade edilmiştir
(Baümler vd., 2016; Baümler vd., 2017; FerreiraDias vd., 2003).

Örneklerin $37 \mathrm{kHz}$ ve $80 \mathrm{kHz}$ frekanslardaki ekstraksiyon verimleri sırasıyla Şekil 1 ve Şekil 2'de gösterilmektedir. Buna göre, etanol veriminin her koşulda hekzana göre düşük bulunduğu ve her iki çözücünün de ekstraksiyon veriminin ise 37 $\mathrm{kHz}$ frekanstan $80 \mathrm{kHz}$ frekansa geçildiğinde düşüş gösterdiği açıkça gözlenmektedir. Benzer şekilde, Muatasim vd. (2018) yaptıkları çalışmada ultrason frekansinı $20 \mathrm{kHz}$ ten $50 \mathrm{kHz} \mathrm{e}$ çıkardıklarında ekstraksiyon veriminin yarıa düştüğünü ifade etmişlerdir. Araştırıcılara göre, ihtiyaç duyulan akustik genişleme için gereken zaman yüksek ultrason frekanslarında sağlanamamakta ve bu yüzden ultrasonik kavitasyonda azalma oluşmaktadır. Çözücülerin farklı ultrasonik koşullarda verimlerinin karşılaştırılması ise etanol için Şekil 3'te, hekzan için ise Şekil 4'te verilmektedir. Buna göre, etanol ekstraksiyonunun verimi $37 \mathrm{kHz}$ frekansta, \%60 güçten \%80 güce çıkıldığında keskin bir artış göstermekle birlikte, benzer bir artış daha 1 lımlı olmakla birlikte hekzan ile ekstrakte edilen grubun veriminde de gözlenmektedir. Şekil 3 ve 4'te gözlendiği üzere frekans artışının verimde azalmaya yol açabileceği önceki çalışmalarda da ifade edilmiştir (Muatasim vd., 2018; Afroz Bakht vd., 2019).

Çizelge 1'e göre, $37 \mathrm{kHz}$ frekansta ve $\% 60$ güç uygulandığında etanol için elde edilen verim değeri ile aynı frekansta diğer güç değerlerinde elde edilen verimler arasındaki farkl111k istatistik olarak önemli bulunmuştur $(P<0.05)$. Frekans 80 kHz'e çıkarıldığında ise farklı güç değerlerinde elde edilen verimler arasında istatistiksel olarak önemli bir fark gözlenmemiştir ( $P$ >0.05). Bununla birlikte etanol kullanılarak farklı frekanslarda ve aynı güç değerlerinde elde edilen verim ortalamaları istatistiksel olarak birbirinden farklı bulunmuştur. Hekzan ekstraksiyonunda ise, $80 \mathrm{kHz}$ frekans ve $\% 60$ güçteki elde edilen verim ortalamas1 (\%29.65), $37 \mathrm{kHz}$ frekansta elde edilen tüm ortalamalardan farklı bulunmuştur. Çift yönlü ANOVA bulgularına göre, ultrasonik güç ve frekans interaksiyonunun etanol ile ekstrakte edilen örneklerin verim ortalamaları arasındaki 
farklara etkilerinin istatistik olarak önemli olduğu $(P<0.05)$ belirlenmiştir. Hekzan ile elde edilen ekstraktların ortalamaları arasındaki fark üzerinde ise sadece uygulanan ultrason frekansinın etkili olduğu ve istatistik olarak önem yarattığ $(P<0.05)$ tespit edilmiştir.

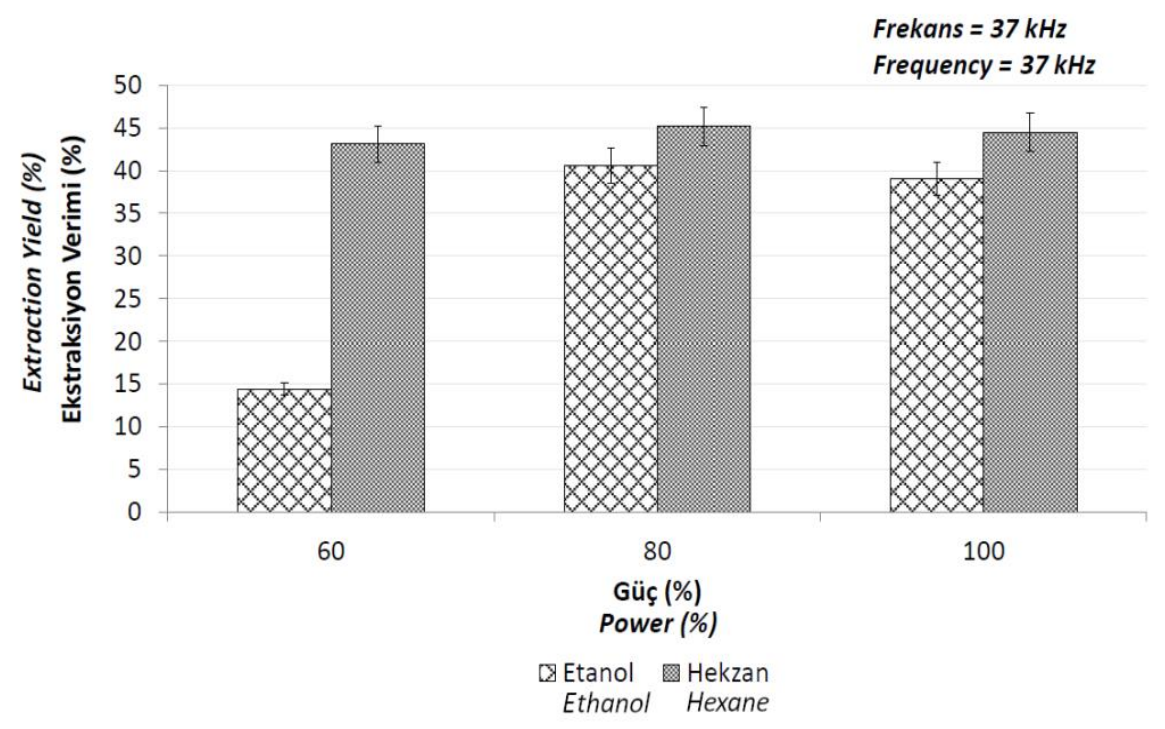

Şekil 1. $37 \mathrm{kHz}$ frekanstaki ekstraksiyon verimleri

Figure 1. Extraction yields at $37 \mathrm{kHz}$.

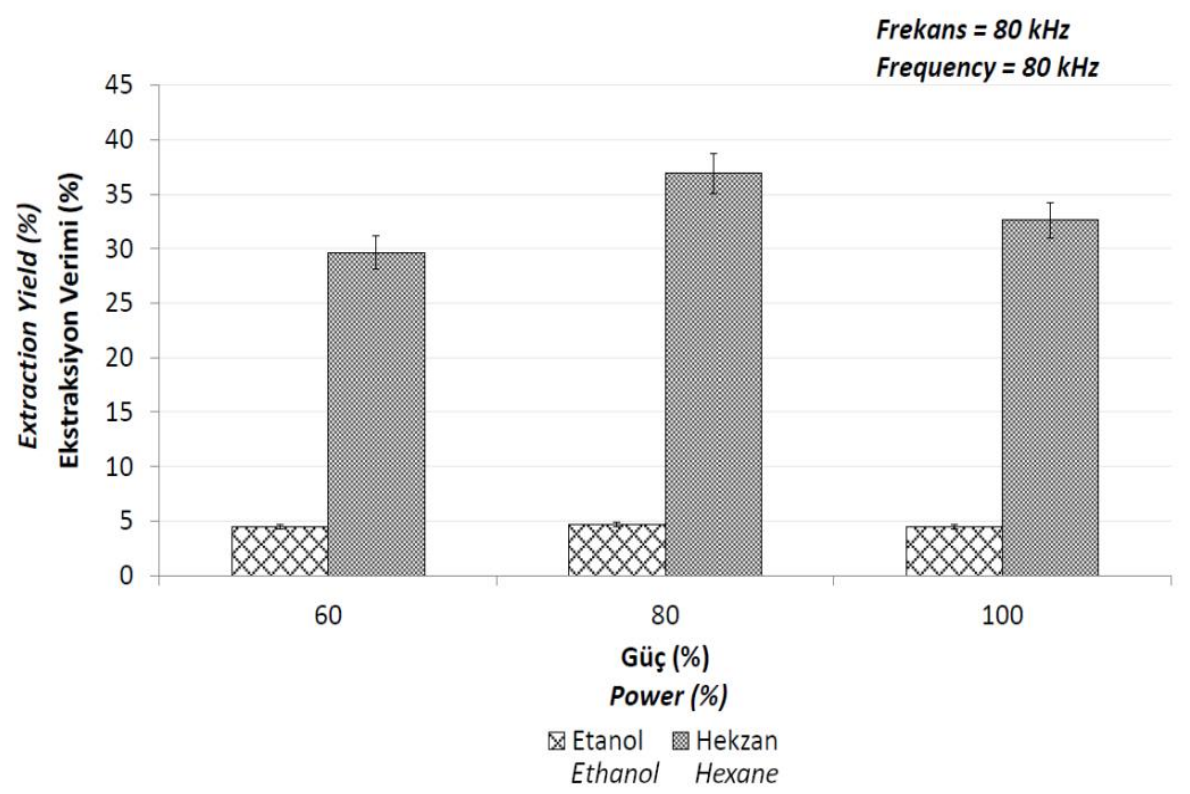

Şekil 2. $80 \mathrm{kHz}$ frekanstaki ekstraksiyon verimleri

Figure 2. Extraction yields at $80 \mathrm{kHz}$. 


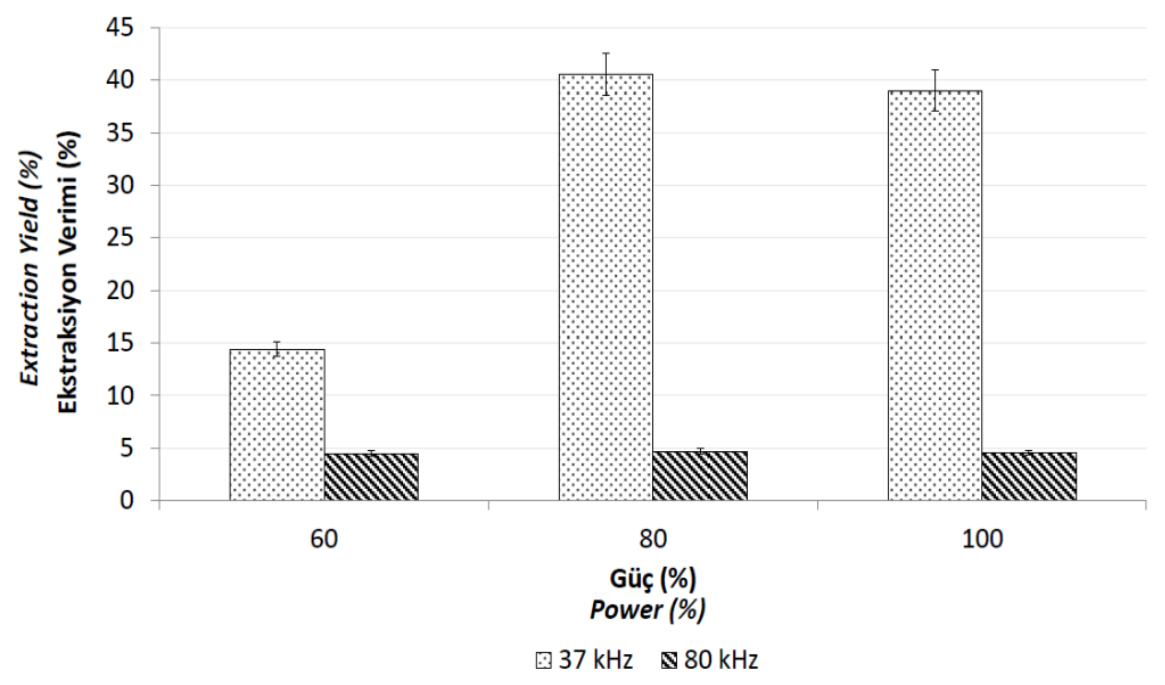

Şekil 3. Etanol ile gerçekleştirilen ekstraksiyonların verimleri

Figure 3. Extraction yields for ethanol

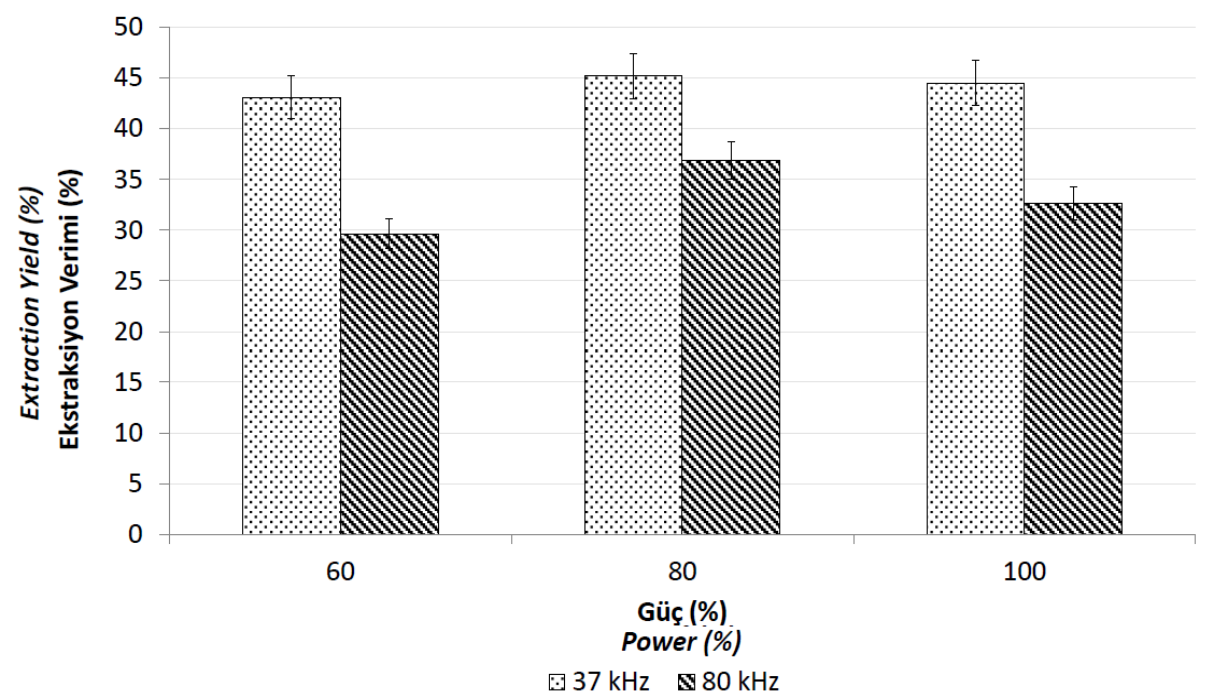

Şekil 4. Hekzan ile gerçekleştirilen ekstraksiyonların verimleri

Figure 4. Extraction yields for bexane

\section{Yağ asidi bileşimi}

Elde edilen ekstraktların yağ asidi bileşimleri incelendiğinde, yer fistığ 1 yağında yaygin olarak bulunan 7 adet yağ asidi tespit edilmiştir. Bunların bir kısmını palmitik asit (C16:0), stearik asit (C18:0), araşidik asit (C20:0) ve behenik asit (C22:0) gibi doymuş yağ asitleri oluşturmakla birlikte, geri kalan kısmını başta yer fistığı yağının başlıca yağ asidi olan oleik asit (C18:1), ve daha az miktarlarda olmakla birlikte linoleik asit (C18:2) ve eikosenoik asit (C20:1) gibi doymamıs yağ asitleri oluşturmaktadır. Yer fistığı yağıyla yapilan diğer çalışmalarda da benzer yağ asitleri tespit edilmiştir (Aluyor vd., 2009; Özcan, 2010; Özcan ve Seven, 2003; Siddeeg ve Xia, 2015). Farkl1 ultrasonik koşullarda elde edilen etanol ve hekzan ekstraktlarının yağ asidi bileşimleri sırasıyla Çizelge 2 ve Çizelge 3'te verilmektedir. Çizelgeler dikkatle incelendiğinde, ekstraksiyonda uygulanan farklı parametrelerin yă̆ asidi bileşimlerinde 
önemli değişikliklere yol açmadığı görülmektedir. Ultrason destekli ekstraksiyon uygulamalarında yağ asidi bileşiminin değişmediği veya çok az etkilendiği önceki araştırıcıların çalışmalarında da ifade edilmiştir (Da Porto vd., 2013; Mohammadpour vd., 2019; Stevanato ve da Silva, 2019). Ekstraktların yağ asidi bileşiminin \%94-95 düzeyinde oleik, linoleik ve palmitik asit toplamından oluştuğu görülmüştür. Uygulanan ultrason gücü ve frekans göz ardı edildiğinde, etanol ile elde edilen ekstraktlarda ortalama oleik asit, linoleik asit ve palmitik asit konsantrasyonlar1 sirasiyla $\% 62.64, \% 21.68$ ve $\% 10.41$ seviyelerinde tespit edilmiştir. Hekzan ile elde edilen ekstraktlarda ise, uygulanan koşullardan bağımsız olarak bu ortalamalar sirasiyla $\% 63.07, \% 21.37$ ve $\% 9.51$ olarak tespit edilmiştir.

Çizelge 2. Farklı ultrasonik koşullarda etanol ile elde edilen ekstraktların yağ asidi bileşimi (\%) Table 2. Fatty acid composition of the ethanol extracts at different ultrasonic conditions (\%)

\begin{tabular}{|c|c|c|c|c|c|c|c|c|}
\hline \multirow{2}{*}{$\begin{array}{l}\text { Frekans } \\
\text { Frequency } \\
(\mathrm{kHz})\end{array}$} & \multirow{2}{*}{$\begin{array}{l}\text { Ultrasonik } \\
\text { güç } \\
\text { Ultrasound } \\
\text { power }(\%)\end{array}$} & \multicolumn{7}{|c|}{$\begin{array}{c}\text { Yağ asidi (\%) } \\
\text { Fatty acids }\end{array}$} \\
\hline & & C16:0 & C18:0 & C18:1 & C18:2 & C20:0 & C20:1 & C22:0 \\
\hline \multirow{3}{*}{37} & 60 & $10.35 \pm 0.10$ & $2.60 \pm 0.15$ & $62.31 \pm 0.21$ & $21.36 \pm 0.19$ & $0.78 \pm 0.04$ & $0.52 \pm 0.00$ & $2.09 \pm 0.48$ \\
\hline & 80 & $10.02 \pm 0.17$ & $2.45 \pm 0.07$ & $62.96 \pm 0.07$ & $21.46 \pm 0.21$ & $0.80 \pm 0.01$ & $0.57 \pm 0.01$ & $1.74 \pm 0.38$ \\
\hline & 100 & $9.98 \pm 0.20$ & $2.67 \pm 0.02$ & $62.83 \pm 0.06$ & $21.56 \pm 0.02$ & $0.77 \pm 0.06$ & $0.45 \pm 0.01$ & $1.73 \pm 0.04$ \\
\hline \multirow{3}{*}{80} & 60 & $10.90 \pm 0.46$ & $2.27 \pm 0.11$ & $62.84 \pm 0.26$ & $21.69 \pm 0.18$ & $0.56 \pm 0.11$ & $0.51 \pm 0.01$ & $1.22 \pm 0.16$ \\
\hline & 80 & $10.58 \pm 0.12$ & $2.53 \pm 0.20$ & $62.54 \pm 0.47$ & $22.11 \pm 0.18$ & $0.70 \pm 0.05$ & $0.51 \pm 0.12$ & $1.04 \pm 0.03$ \\
\hline & 100 & $10.62 \pm 0.19$ & $2.45 \pm 0.16$ & $62.37 \pm 0.23$ & $21.92 \pm 0.05$ & $0.63 \pm 0.16$ & $0.52 \pm 0.07$ & $1.49 \pm 0.07$ \\
\hline
\end{tabular}

Veriler ortalama \pm standart hata şeklinde ifade edilmiştir $(\mathrm{n}=2)$.

$V$ alues are expressed as mean \pm std.error $(n=2)$.

Çizelge 3. Farklı ultrasonik koşullarda hekzan ile elde edilen ekstraktların yağ asidi bileşimi (\%)

Table 3. Fatty acid composition of the hexane extracts at different ultrasonic conditions (\%)

\begin{tabular}{|c|c|c|c|c|c|c|c|c|}
\hline \multirow{2}{*}{$\begin{array}{c}\text { Frekans } \\
\text { Frequency } \\
(\mathrm{kHz})\end{array}$} & \multirow{2}{*}{$\begin{array}{l}\text { Ultrasonik } \\
\text { güç } \\
\text { Ultrasound } \\
\text { power }(\%)\end{array}$} & \multicolumn{7}{|c|}{$\begin{array}{c}\text { Yağ asidi (\%) } \\
\text { Fatty acids }\end{array}$} \\
\hline & & C16:0 & C18:0 & C18:1 & C18:2 & C20:0 & $C 20: 1$ & $C 22: 0$ \\
\hline \multirow[b]{2}{*}{37} & 60 & $9.49 \pm 0.09$ & $2.65 \pm 0.03$ & $63.07 \pm 0.32$ & $21.48 \pm 0.07$ & $0.82 \pm 0.15$ & $0.52 \pm 0.03$ & $1.97 \pm 0.26$ \\
\hline & $\begin{array}{c}80 \\
100\end{array}$ & $\begin{array}{l}9.47 \pm 0.02 \\
9.61 \pm 0.01\end{array}$ & $\begin{array}{l}2.59 \pm 0.08 \\
2.57 \pm 0.00\end{array}$ & $\begin{array}{l}62.88 \pm 0.10 \\
62.87 \pm 0.18\end{array}$ & $\begin{array}{l}21.39 \pm 0.04 \\
21.33 \pm 0.26\end{array}$ & $\begin{array}{l}0.80 \pm 0.00 \\
0.83 \pm 0.02\end{array}$ & $\begin{array}{l}0.66 \pm 0.02 \\
0.55 \pm 0.19\end{array}$ & $\begin{array}{l}2.21 \pm 0.02 \\
2.24 \pm 0.25\end{array}$ \\
\hline \multirow[b]{2}{*}{80} & 60 & $9.52 \pm 0.03$ & $2.60 \pm 0.04$ & $63.60 \pm 0.12$ & $21.09 \pm 0.04$ & $0.79 \pm 0.07$ & $0.66 \pm 0.01$ & $1.73 \pm 0.03$ \\
\hline & $\begin{array}{c}80 \\
100\end{array}$ & $\begin{array}{l}9.34 \pm 0.06 \\
9.62 \pm 0.05\end{array}$ & $\begin{array}{l}2.62 \pm 0.07 \\
2.62 \pm 0.02\end{array}$ & $\begin{array}{l}62.73 \pm 0.22 \\
63.25 \pm 0.02\end{array}$ & $\begin{array}{l}21.41 \pm 0.04 \\
21.52 \pm 0.13\end{array}$ & $\begin{array}{l}1.02 \pm 0.10 \\
0.82 \pm 0.09\end{array}$ & $\begin{array}{l}0.76 \pm 0.17 \\
0.53 \pm 0.05\end{array}$ & $\begin{array}{l}2.13 \pm 0.09 \\
1.63 \pm 0.01\end{array}$ \\
\hline
\end{tabular}

Veriler ortalama \pm standart hata şeklinde ifade edilmiştir $(\mathrm{n}=2)$.

Values are expressed as mean \pm std.error $(n=2)$.

Uygulanan ekstraksiyon yönteminden bağımsız olarak, genel olarak yağ asidi bileşiminde önemli farklar yaratmamakla birlikte palmitik asidin etanol ekstraktlarında ve oleik asidin hekzan ekstraktlarında bir miktar daha yüksek bulunduğu literatürdeki çalışmalarla da kanıtlanmıştır (Breil vd., 2016; Li vd., 2014; Zhuang vd., 2018). Yer fistığ1 yağının bir diğer ayırt edici yağ asidi olan araşidik asit (C20:0) miktarının da uygulanan farklı işlem parametrelerinden etkilenmediği gözlenmiş olup, etanol ekstraktlarında ortalama $\% 0.71$ ve hekzan ekstraktlarında ise ortalama \%0.85 düzeyinde araşidik asit tespit edilmiştir. Bununla birlikte diğer tespit edilmiş yağ asitleri olan stearik asit (C18:0), eikosenoik asit (C20:1) ve behenik asit (C22:0) ortalama miktarlar1 ise etanol ve hekzan ekstraktlarında sirasiyla; \%2.50-\%0.51$\% 1.55$ ve $\% 2.61-\% 0.61-\% 1.98$ olarak tespit edilmiştir. 
İstatistik analiz verilerine göre, ekstraksiyon sırasında uygulanan ultrasonik güç ve frekans interaksiyonlarının hem etanol hem de hekzan ekstraktlarındaki oleik asit konsantrasyonlanında istatistiksel olarak önemli bir fark yaratmadığ1 belirlenmiştir $(P>0.05)$. Bununla birlikte, oleik asit konsantrasyonları arasındaki fark üzerine frekans ve güç uygulamalarının bireysel etkilerinin de istatistik olarak önemsiz olduğu tespit edilmiştir $(P>0.05)$.

\section{SONUÇ}

Elde edilen bulgular sonucunda, yer fistı̆̆1 yağının ultrason destekli ekstraksiyonuna ilişkin verimlerin frekans sabit tutulduğunda, uygulanan gücün belli bir seviyeye kadar artışıyla bir miktar arttığı, fakat maksimum güç uygulandığında ise bir miktar düştüğü tespit edilmiştir. Eşit güç uygulamasında ise, düşük frekanstaki ekstraksiyonlarda hem etanol hem hekzan için yüksek frekansa göre daha yüksek verim elde edilmiştir. Çözücülerin kıyaslanması sonucunda ise, etanol ile elde edilen ekstraktların verimlerinin her koşulda hekzan ekstraksiyonu ile elde edilen örneklere göre daha düşük olduğu belirlenmiştir. Uygulanan ultrason işlem koşullarının yer fistığ yağ asidi bileşimi üzerine önemli bir etkisi olmadığ yapılan kromatografik analiz sonucunda tespit edilmiştir. Ekstraktlardaki baskın yağ asidi olan oleik asit ortalamalarının hekzan ekstraktlarında etanol ekstraktlarına göre bir miktar fazla olduğu, bununla birlikte palmitik asit ortalamalarında ise bir miktar düşüş olduğu belirlenmiştir. Yapılan istatistiksel analiz sonrasinda, ultrason destekli ekstraksiyona ait farklı frekans ve ultrasonik güçlerin bireysel etkilerinin elde edilen ekstraktlara ait oleik asit konsantrasyonları üzerinde önemsiz olduğu sonucuna varılmıştır $(P>0.05)$. Tüm bu bulgular 1şığında, yenilikçi bir teknoloji olan ultrason tekniğinin yer fistığ1 yağ1 ekstraksiyonunda kullanılabilirliğinin yanında, farklı frekans ve güç uygulamalarının ekstraksiyon verimi ve yağ asidi bileşimi üzerine olan etkileri ortaya konmuştur. Ayrıca, geleneksel çözücü olan hekzanın olumsuz etkilerine alternatif olarak, biyolojik kaynaklardan kolaylıkla elde edilebilen etanolün bu işlem doğrultusunda kullanılabilirliği araştırılmışır. Elde edilen bulgulara göre tüm denemelerde etanolün ekstraksiyon verimlerinin hekzana göre düşük bulunması ve etanolün hekzandan daha az seçici bir çözücü olması sebebiyle, bu çözücünün yağ ekstraksiyonu amacıyla kullanımı için daha fazla araştırmaya ihtiyaç duyulduğu kanısına varılmıştır. $\mathrm{Bu}$ araştırmadan elde edilen bulguların ileriki araştırmalara ve endüstriyle uygulamalara $1 s ̧ 1 k$ tutması öngörülmektedir.

\section{KAYNAKLAR}

Afroz Bakht, M., Geesi, M.H., Riadi, Y., Imran, M., Imtiyaz Ali, M., Ahsan, M.J., \& Ajmal, N. (2019). Ultrasound-assisted extraction of some branded tea: Optimization based on polyphenol content, antioxidant potential and thermodynamic study. Saudi J Biol Sci 26(5): 10431052, doi:10.1016/j.sjbs.2018.07.013

Aluyor, E., Aluyor, P., Ozigagu, C. (2009). Effect of refining on the quality and composition of groundnut oil. Afr J Food Sci 3(8): 201-205.

Anonim (2012). Türk Gıda Kodeksi. Bitki Adı ile Anılan Yağlar Tebliği (2012/29). Gida Tarım ve Hayvancilık Bakanlığı 12 Nisan 2012 tarih ve 28262 sayllı Resmî Gazete, Ankara.

Baümler, E.R., Carrín, M.E., Carelli, A.A. (2016). Extraction of sunflower oil using ethanol as solvent. J Food Eng 178: 190-197, doi:10.1016/j.jfoodeng.2016.01.020

Baümler, E.R., Carrín, M.E., Carelli, A.A. (2017). Diffusion of tocopherols, phospholipids and sugars during oil extraction from sunflower collets using ethanol as solvent. J Food Eng 194: 18, doi:10.1016/j.jfoodeng.2016.09.003

Breil, C., Meullemiestre, A., Vian, M., Chemat, F. (2016). Bio-Based Solvents for Green Extraction of Lipids from Oleaginous Yeast Biomass for Sustainable Aviation Biofuel. Molecules 21(2): 196, doi:10.3390/molecules21020196

Chanioti, S., Tzia, C. (2017). Optimization of ultrasound-assisted extraction of oil from olive pomace using response surface technology: Oil recovery, unsaponifiable matter, total phenol content and antioxidant activity. LWT - Food Sci Technol 79: 178-189, doi:10.1016/j.lwt. 2017.01.029 
Chemat, F., Tomao, V., Virot, M. (2008). Ultrasound-Assisted Extraction in Food Analysis. In: Handbook of Food Analysis Instruments, Ötleş, S. (Ed.), Boca Raton, FL: CRC Press, pp. 85-103

Crevel, R.W.R., Kerkhoff, M.A.T., Koning, M.M.G. (2000). Allergenicity of refined vegetable oils. Food Chem Toxicol, 38(4), 385-393, doi:10.1016/S0278-6915(99)00158-1

Da Porto, C., Porretto, E., Decorti, D. (2013). Comparison of ultrasound-assisted extraction with conventional extraction methods of oil and polyphenols from grape (Vitis vinifera L.) seeds. Ultrason Sonochem 20(4): 1076-1080, doi:10.1016/j.ultsonch.2012.12.002

Dong, J., Liu, Y., Liang, Z., Wang, W. (2010). Investigation on ultrasound-assisted extraction of salvianolic acid B from Salvia miltiorrhiza root. Ultrason Sonochem 17(1): 61-65, doi:10.1016/j.ultsonch.2009.05.006

Escorsim, A.M., da Rocha, G., Vargas, J.V.C., Mariano, A.B., Ramos, L.P., Corazza, M.L., Cordeiro, C.S. (2018). Extraction of Acutodesmus obliquus lipids using a mixture of ethanol and hexane as solvent. Biomass Bioenergy 108: 470-478, doi:10.1016/j.biombioe.2017.10.035

FAO (2019). FAOSTAT. Food and Agriculture Organization of the United Nations, Roma, İtalya.

Ferreira-Dias, S., Valente, D.G., Abreu, J.M.F. (2003). Comparison between ethanol and hexane for oil extraction from Quercus suber L. fruits. Grasas Aceites 54(4): 378-383, doi:10.3989/gya.2003.v54.i4.225

ISO (2011). Animal and vegetable fats and oils Gas chromatography of fatty acid methyl esters Part 2: Preparation of methyl esters of fatty acids. ISO 12966-2:2011. Geneva, Switzerland: ISO.

Kadiroğlu, A. (2018). Yerfıstı̆̆1 Yetiştiriciliği. Bat1 Akdeniz Tarımsal Araştırma Enstitüsü Müdürlüğü. https://arastirma.tarimorman.gov.tr/batem/Bel geler/Kutuphane/Teknik $\% 20$ Bilgiler/yerfistigi $\%$ 20yetistiriciligi.pdf (Erişim tarihi: 8 Ekim 2019).
Li, H., Pordesimo, L., Weiss, J. (2004). High intensity ultrasound-assisted extraction of oil from soybeans. Food Res Int 37(7): 731-738, doi:10.1016/j.foodres.2004.02.016

Li, Y., Fine, F., Fabiano-Tixier, A.-S., Abert-Vian, M., Carre, P., Pages, X., Chemat, F. (2014). Evaluation of alternative solvents for improvement of oil extraction from rapeseeds. $C$ R Chim 17(3): 242-251, doi:10.1016/j.crci.2013.09.002

Ma, Y., Wu, X., Zhao, L., Wang, Y., Liao, X. (2019). Comparison of the compounds and characteristics of pepper seed oil by pressureassisted, ultrasound-assisted and conventional solvent extraction. Innov Food Sci Emerg 54: 78-86, doi:10.1016/j.ifset.2019.03.011

Mohammadpour, H., Sadrameli, S.M., Eslami, F., Asoodeh, A. (2019). Optimization of ultrasoundassisted extraction of Moringa peregrina oil with response surface methodology and comparison with Soxhlet method. Ind Crop Prod 131: 106-116, doi:10.1016/j.indcrop.2019.01.030

Muatasim, R., Ma, H., Yang, X. (2018). Effect of multimode ultrasound assisted extraction on the yield of crude polysaccharides from Lycium Barbarum (Goji). Food Sci Technol 38: 160-166, doi:10.1590/1678-457X.14417

Onat, B. (2018). The determination of Tocopherol composition of some peanut cultivars grown in main crop growing conditions in Cukurova Region. Acta Biol Turc 31(2): 62-68

Özcan, M.M. (2010). Some nutritional characteristics of kernel and oil of peanut (Arachis hypogaea L.). J Oleo Sci 59(1): 1-5, doi:10.5650/jos.59.1

Özcan, M., Seven, S. (2003). Physical and chemical analysis and fatty acid composition of peanut, peanut oil and peanut butter from ÇOM and NC-7 cultivars. Grasas Aceites 54(1): 12-18.

Perrier, A., Delsart, C., Boussetta, N., Grimi, N., Citeau, M., Vorobiev, E. (2017). Effect of ultrasound and green solvents addition on the oil extraction efficiency from rapeseed flakes. Ultrason Sonochem 39: 58-65, doi:10.1016/j.ultsonch.2017.04.003 
Rodriguez-Estrada, M.T., Paciulli, M., Cerretani, L., Chiavaro, E. (2017). Production of Vegetable Oils from Fruits, Oilseeds, and Beans: Conventional Processing and Industry Techniques. In: Edible Oils: Extraction, Processing, and Applications, Chemat, S. (Ed.), Boca Raton, FL: CRC Press, pp. 1-34

Sbihi, H.M., Nehdi, I.A., Mokbli, S., RomdhaniYounes, M., Al-Resayes, S.I. (2018). Hexane and ethanol extracted seed oils and leaf essential compositions from two castor plant (Ricinus communis L.) varieties. Ind Crop Prod 122: 174181, doi:10.1016/j.indcrop.2018.05.072

Siddeeg, A., Xia, W. (2015). Oxidative stability, chemical composition and organoleptic properties of seinat (Cucumis melo var. tibish) seed oil blends with peanut oil from China.J Food Sci Technol 52(12): 8172-8179, doi:10.1007/s13197-015-1889-x

Stevanato, N., da Silva, C. (2019). Radish seed oil: Ultrasound-assisted extraction using ethanol as solvent and assessment of its potential for ester production. Ind Crop Prod 132: 283-291, doi:10.1016/j.indcrop.2019.02.032
Taticchi, A., Selvaggini, R., Esposto, S., Sordini, B., Veneziani, G., Servili, M. (2019). Physicochemical characterization of virgin olive oil obtained using an ultrasound-assisted extraction at an industrial scale: Influence of olive maturity index and malaxation time. Food Chem 289: 7-15, doi:10.1016/j.foodchem.2019.03.041

Topdaş, E.F., Ertugay, M.F. (2013). Kayısıların Ultrases Yardimlı Ozmotik Kurutulması. GIDA, 38(5): 299-306, doi:10.5505/gida.2013.02886

Tüfekçi, S., Özkal, S.G. (2015). Application of Ultrasound in Food Drying. Pamukkale Univ Muh Bilim Derg 21(9): 408-413, doi:10.5505/pajes.2015.05902

Zhuang, X., Zhang, Z., Wang, Y., Li, Y. (2018). The effect of alternative solvents to n-hexane on the green extraction of Litsea cubeba kernel oils as new oil sources. Ind Crop Prod 126: 340-346, doi:10.1016/j.indcrop.2018.10.004 